\title{
Measuring Digital Transformation Maturity of Supply Chain
}

\author{
Krešimir Buntak, Matija Kovačić, Maja Mutavdžija
}

\begin{abstract}
Digital transformation signifies changes in all components and systems of the supply chain. It is also a strategic decision of the organization which, in the long run, can result in the creation of competitive advantage in the market. Digital transformation is affecting all organizations, regardless of their activity. Digital transformation of the supply chain involves the use of industry 4.0 based technologies as well as the replacement of traditional practices with new ones based on digital solutions. The implementation of digital solutions, such as artificial intelligence, loT, cloud computing, etc., therefore, improve communication between stakeholders in the supply chain, as well as improve efficiency and effectiveness. When conducted, digital transformation must be measured by different levels of maturity. In this paper, authors research current models of measuring digital transformation maturity in supply chain and propose a new model based on identified theories and needs.
\end{abstract}

Keywords: change management; digital transformation; maturity models; supply chain

\section{INTRODUCTION}

A supply chain is a group of interconnected stakeholders. Each stakeholder has a task to add value to raw materials that are in the supply chain and to reduce the costs associated with carrying out the activities necessary to add value [1]. To reduce costs and to increase the efficiency of the supply chain, each organization, that is part of the supply chain, can implement some of the technologies that are related to Industry 4.0. i.e. to digital transform the traditional supply chain. Digital transformation means changes in the system that results from implementing technological improvements. The term technological improvements mean the application of automatic and robotic systems which allows the integration of physical infrastructure and suprastructure into a network, as well as the intercommunication between connected infrastructure and suprastructure [2]. The need for digital transformation is arising from increasing expectations from various interested parties that place different requirements on the supply chain, like ensuring the availability of products or raw materials, etc. Furthermore, the requirements of interested parties can be related to the reduction of negative environmental impact, using machines and devices that use alternative energy sources for their work, etc. [3]. All stakeholders in the supply chain must adapt to the described turbulent environment from which are arising different requirements of interested parties. Most important, organizations in the supply chain must develop a competitive advantage and to decrease operational costs and increase efficiency. One way to adapt to that requirement is to digitally transform businesses.

To measure how successful organizations made digital transformation there are different models. In general, the organization can measure the success of making digital transformation through maturity levels. The maturity level is divided into different levels that, in almost all cases, mark level 1 as the beginning of transformation and level 5 or higher as the final stage of transformation. [4]

This paper is secondary research that aims to identify existing models of measuring the maturity of digital transformation and creating a new one.

Paper is divided into six chapters.
The second chapter describes system theory and systematic approach to the organization and its importance within the process of digital transformation.

The third chapter describes the importance of sustainable development of the organization.

The fourth chapter is about digital transformation and Industry 4.0 and its importance for today's busses.

The fifth chapter describes digital transformation of the supply chain.

The sixth chapter describes the practical impact of this research and its limitations.

\section{THE IMPORTANCE OF A SYSTEMATIC APPROACH IN DIGITAL TRANSFORMATION}

A systematic approach is based on general system theory that is created for better understanding different science disciplines i.e. common language for communication between different science disciplines. System theory describes the system as the group of subsystems and relations between subsystems. All subsystems in the system are mutually related and changes in one subsystem can impact the change in other subsystems. Furthermore, system theory emphasizes that the system exists in mesosystem and mesosystem exist in the macrosystem. All mentioned components are mutually connected and can impact on each other [5]. When it comes to practical implications of system theory, the supply chain can be viewed as a mesosystem that exists within the macrosystem. Macrosystem is related to the general environment from wich forces like legislation, changes in technologies, economic changes and other, act on organization. Furthermore, the supply chain consists of many different stakeholders i.e. organizations that can be viewed as systems. So, in the context of relations that are emphasized in general system theory, if the supply chain is affected with some anomaly, the anomaly will affect all organizations in the supply chain.

Furthermore, system theory highlights:

- every system tends to grow and develop. That is also one of the fundamental characteristics of the supply chain as a system, 
- all the elements in the system are interconnected, and as such, the system consists of several different elements that affect each other and interact with each other,

- the goal of each system is to create, i.e. ensure that the desired output is generated, using the resources used at the output,

- entropy in the system is a common occurrence that results from changes in the environment of the system. Any change in the environment can cause a crisis in the system if the system does not develop an adequate response to it,

- each system needs to be managed because if the system is not managed, as a consequence, it may not be possible to achieve the desired system goal [6].

So, according to the system theory, the partial digital transformation of one stakeholder in the supply chain and improvement of its performance will not affect the overall performance of the entire supply chain. It is necessary to optimize and digital transform supply chain as a whole to improve the overall performance of it. Each supply chain tends to grow and develop but it is necessary to ensure its manageability because the loss of control in one of the components will result in the risk of losing control of the entire supply chain.

\section{INTRODUCTION TO DIGITAL TRANSFORMATION}

Digital transformation involves specific changes that can affect the whole organization. It is also a strategic decision of the organization which, in the long run, can result in the creation of competitive advantage in the market. Digital transformation requires a change in the current organizational business paradigm and a change to create a new organizational culture that will shape the way the organization operates after performed digital transformation [7]. To perform the digital transformation, the organization must ensure technical and technological competence because without such competencies organizations can not implement innovations such as the Internet of Things (IoT), Artificial Intelligence (AI), Big Data, etc. [8]. Technical competence is related to the existence of machines and devices in an organization, and technological competence is related to the knowledge of how to do something or how to use machines and devices [9]. Accordingly, digital transformation requires major changes in the organization which can lead to resistance of organizational employees. Resistance can occur because of the changes in ways of doing business and fear of losing the control in an organization with implementation of automated systems. For this reason, digital transformation of organization needs to be properly communicated within the organization to reduce the risk of employee resistance.

Digital transformation is done in phases. Current phase of the digital transformation of the organization determines the digital maturity of the organization. So, the digital maturity of an organization is determined with the usage of digital technologies within organizational processes. Furthermore, with a higher level of digital maturity organization can increase the quality of the product or service provided to customers and users and also the efficiency of business processes [10].

It is important to highlight that digital transformation can be determined by the innovations that employees in organization develop [11].

Digital transformation is affecting all organizations, regardless of the product and services they provide. In the context of manufacturing organizations, digital transformation involves the use of automated and robotic manufacturing systems. On the other hand, digital transformation in the logistics sector involves the application of automated warehouse systems as well as sensor-based technologies that enable the monitoring of the performance that logistics processes develop, etc.

\section{DIGITAL TRANSFORMATION OF THE SUPPLY CHAIN AND RELATED TEHNOLOGIES}

As mentioned in chapter 1, supply chain consists of different organizations that are mutually connected. Each organization in the supply chain has a different task, and the whole supply chain has to procure all raw materials, products, and services that are necessary to ensure the normal functioning of other organizations and society as a whole.

Digital transformation of the supply chain involves the use of industry 4.0 based technologies as well as the replacement of traditional practices with new ones based on digital solutions. Digital solutions can increase the efficiency of the supply chain and also decrease costs. With the usage of some of the technologies, such as AI, organizations in the supply chain can simulate and predict demand for goods and services. Furthermore, AI can help in optimizing transport routes and managing warehouses, etc. Implementation and usage of AI are determined with the technical, technological and competence of employees in the organization.

Other technological innovations, except AI, that can be implemented in the supply chain and organization within the supply chain are:

- collaborative equipment: means the use of automated systems such as robots and drones. Automated systems can be used in the warehouse to reduce the need for human labor which means decreasing costs and higher reliability of the system. If such system is paired with AI, then AI can optimize the functioning of automated systems, like robots. When it comes to drones, drones can be used to transport goods between organizations in the supply chain or to deliver goods to the customer. It is possible to create a system in which AI manages robots to transport goods from the warehouse to the drones and then drones transport goods to the customer [12],

- additive manufacturing: involves the use of a 3D printer for creating products. In other words, an organization that owns a $3 \mathrm{D}$ printer can print the product according to the specification that other organization provides. In supply chain that means less need for transportation because it is possible to send a specification of the product to the organization who ask for it in the supply chain and that organization can print product accordingly to specifications that organization receive. But it is 
important to highlight the need for raw material which is used to print product i.e. functioning of $3 \mathrm{D}$ printer. This kind of technology can be used, for example, in healthcare for printing implants [13],

- Internet of Things (IoT): involves the creation of a network between infrastructure and suprastructure as well as communication between the same. Examples of using this kind of technologies are tracking the goods in the transportation process, tracking the movement of the robots in the warehouse and the possibility of managing the robots, etc. For the normal functioning of IoT, it is necessary to ensure sensors that will be implemented in robots, goods or vehicles. So, based on the sensor readings, certain machines and devices that perform certain activities in the process are activated [14],

- Blockchain: with the development of the supply chain there is a need for better manageability of it and decreasing risks and costs of processes in it. Furthermore, there is also a need for better recording and dissemination of information. One of the technologies that can help organizations within the supply chain is blockchain. Blockchain enables creating an unique database that can be managed decentralized so every organization within the supply chain can make changes in it. One of the main advantages of using blockchain in the supply chain is the fact that all created information have a copy that is stored in databases of all organizations in the supply chain. Furthermore, blockchain enables substitution of traditional systems of communication as electronic data interchange and decreasing risks and increasing the reliability of the supply chain [2].

Therefore, in practice, there are many more technologies that can be implemented in the supply chain such as cloud computing, business intelligence, big data, etc. All of the mentioned technologies can increase the efficiency of the supply chain and decrease costs in the long run [15].

Using such technologies may enable improvements to the logistics processes taking place in the supply chain through the creation of a virtual model of the logistics system. In the virtual model of the logistics system is possible to take different tests related to searching for possible improvements and the testing result of implemented improvements [16].

\subsection{Digital Supply Chain}

When it comes to defining digital supply chain it must be highlighted that digital supply chain is related to supply chain which uses a different kind of technologies and some of them are mentioned in chapter 5 .

The traditional supply chain is based on a functional geographical structure and can often be displayed in silos. Such a structure is often highly formalized through the use of physical documentation, which can significantly slow down the processes in it [17]. On the other hand, the digital supply chain is much less formalized in regards to traditional because of using technology for digital communication.
Furthermore, the digital supply chain can be displayed as a virtual structure with all processes that are taking place in it and with data collected using sensors and stored in digital databases. Such data can be used for decreasing costs and increasing efficiency which is the goal of each supply chain, digital and traditional [18].

For making supply chain digital it is necessary to conduct digital transformation and to implement technologies which are described in chapter 4 . So, it can be said that the digital supply chain is based on:

- Technology: digital transformation means the implementation of technologies such as IoT, AI, etc. With the implementation of such technologies there is a possibility and chance to increase the performance of processes within the supply chain. Without implementation technologies, the digital supply chain does not exist.

- Integration: indicates increased collaboration between organizations in the supply chain. With increasing collaboration there is also increasing in transparency, better functioning of processes within the supply chain and also the possibility to create better collaboration,

- Collaboration: means better coordination in the process of product planning and development, dissemination of information as well as the overall functioning of the supply chain,

- Coordination: implies coordination of activities carried out in the supply chain with the aim of increasing the efficiency and effectiveness [17].

Implementation of digital technologies also have a higher risk associated with the possibility that the information contained in the digital supply chain may be exposed to external influence, i.e that third parties may be able to misuse such information. Accordingly to identify risk of leaking information, the organization must develop mechanisms to reduce such risk, which is an imperative given the sensitivity of the information in the supply chain and the imperative to protect stakeholder-related data.

\subsection{Existing Models of Digital Supply Chain Maturity}

The maturity of the digital supply chain is determined by several implemented digital technologies i.e. digitalization of processes within the supply chain. There are many different approaches for measuring the maturity of the digital supply chain and one of the models is described by Salmon (2019).

Accordingly to Salamon [19] the maturity of the digital supply chain can be divided into four as shown in Tab. 1 .

Exsisting model that is described by Salamon (2019) do not include all possibilities that tehnologies of industry 4.0 i.e. digital transformation provides. Furthermore, existing model do not include zero level of maturity, holistic wiev and view form perspective of individual organization. Accordingly to that fact, there is need for developing new model for identifying maturity of digital supply chain.

Furthermore, through research it is identified that there is a lack of maturity levels of digital transformation but there are several different authors that are describing what 
indicators are measured through maturity level of digital transformation. Most of the authors indicate that the digital culture, technology, operations and processes, strategy, organization, digital skills, innovation, etc. are contained in their models of maturity [20].

Table 1 Maturity levels according to Salamon (2019)

\begin{tabular}{|c|l|}
\hline Maturity level & $\begin{array}{l}\text { Collaboration within an organization: As already } \\
\text { emphasized, digital transformation is a complex process } \\
\text { that needs to be conducted in all of the organizations in } \\
\text { the supply chain. For conducting transformation it is } \\
\text { necessary to ensure efficient and effective change } \\
\text { management that will enable gradual transformation in } \\
\text { the chain. So, the first step means identification of } \\
\text { opportunities for digital transformation and places in the } \\
\text { organizational processes where digitization can be } \\
\text { carried out. }\end{array}$ \\
\hline 1 & $\begin{array}{l}\text { Networked Supply Chain: The possibility for } \\
\text { organizations participating in the market as individuals } \\
\text { to develop a competitive advantage in the market is } \\
\text { significantly less than the possibility for networked } \\
\text { organizations. Accordingly to this, in level } 2 \text { of maturity, } \\
\text { organizations in the supply chain are networked and are } \\
\text { using digital technologies for networking like } \\
\text { blockchain, cloud computing, etc. }\end{array}$ \\
\hline 3 & $\begin{array}{l}\text { Full integration of customer requirements: The use of } \\
\text { digital technologies enables a much better understanding } \\
\text { and gathering of information on the requirements that } \\
\text { stakeholders place on organizations as well as on the } \\
\text { entire supply chain. The supply chain, as such, exists to } \\
\text { provide all the necessary resources and to meet the } \\
\text { demands of stakeholders. In level 3 of maturity, in the } \\
\text { organization in the supply chain use digital technologies } \\
\text { as well as software solutions such as computer-aided } \\
\text { programs for order prediction, simulation, IoT, RFID, } \\
\text { etc }\end{array}$ \\
\hline $\begin{array}{l}\text { Predictability: Forth level of maturity means that } \\
\text { organizations in the supply chain are using digital } \\
\text { technologies to predict further developments in the } \\
\text { market and also to predict risks and possibilities for } \\
\text { further development and optimiziation of the supply } \\
\text { chain }\end{array}$ \\
\hline 3
\end{tabular}

When it comes to proposed models for measuring digital transformation maturity of the supply chain, it is identified that there are almost no authors that describe models for measuring mentioned maturity.

With development of Industry 4.0 and increasing need for finding out new ways for increasing efficiency and decreasing costs, supply chains are tending to conduct digital transformation. For success in such transformation, there is a need for a model that will provide measuring how successful digital transformation is carried out and also need for measuring the maturity of the organizational system after transforming it into a digital one.

\subsection{Proposed Model for Digital Supply Chain Maturity}

As described at the end of chapter 4.2, there is a need for developing a new maturity model that will include zero level of maturity and situations in which only one of the organizations that is part of a supply chain, has conducted digital transformation. Furthermore, the new model of maturity described in Tab. 2 includes a synergy that is created through the collaboration between different kinds of technologies that are implemented within the supply chain and using technologies for the fulfillment of specific requirements of interested parties.

Table 2 Maturity levels of digital supply chain

\begin{tabular}{|l|l|}
\hline Maturity level & \multicolumn{1}{|c|}{ Description } \\
\hline Digital transformation is not conducted. The supply \\
chain is traditionally organized. All communication is \\
carried out by traditional ways that in most cases \\
means using e-mails and documents. Level 0 also \\
describes cases in which only one of the organizations \\
within the supply chain conducted digital \\
transformation but the organization can not use its \\
advantage and implemented technology in full \\
potential because other organizations are not \\
implementing digital technologies.
\end{tabular}

It is also necessary to emphasize that organizations, that is, the supply chain as a whole, are constantly adapting to new technologies that are evolving and emerging. Adaptation to such technologies is necessary to retain the once acquired 
competitive advantage but also to create new opportunities for creating new competitive advantage.

As shown in Tab. 1, the maturity level of the digital supply chain is divided into 6 levels. Every level has different characteristics and different level of synergy between implemented technologies and humans or organizational system with different risks. There are five indicators measured within the proposed model and those are as follows:

- Conduction of digital transformation

- Communication in organization and between organizations within the supply chain

- Creation of new bussiness paradigms

- Synergy in organization and between organizations within the supply chain

- New technologies used for processes optimization.

With increasing the level of maturity there is also an increased risk of substituting humans from the system and the possibility for AI to take place in managing the entire system. It should be highlighted that digital transformation has different advantages that are related to decreasing costs and to increase profit. But there are many different kinds of challenges and problems that are related to the role that humans have in such a system.

\section{CONCLUSION}

The supply chain is a set of interconnected stakeholders who have the basic task of providing all the necessary resources to meet the requirements of the stakeholders, and especially the customer. The impact of the development of Industry 4.0 , as a consequence, has the importance of implementing new types of technologies in the organization, and such technologies will allow optimization of the processes taking place in the supply chain. Supply chain optimization is of particular importance because of the need to reduce costs. The implementation of digital solutions, such as artificial intelligence, IoT, cloud computing, etc., as a consequence have improving communication between stakeholders in the supply chain, as well as improve efficiency and effectiveness.

An organization's digital transformation can be viewed through its maturity level. With a higher maturity level, organizations have a higher number of implemented technologies and higher performance of processes. Furthermore, because the supply chain is a system that is compound from many different organizations, for supply chain is general system theory valid, and that theory implies that the digital transformation of one organization in the supply chain will not have a significant impact on the overall performance of supply chain.

To measure the digital transformation maturity of the supply chain there is not an adequate model that is based on a scientific approach. Furthermore, several different models are created by commercial organizations that are in most cases consult agencies for digital transformation. That kind of models are not scientifically proven and there is a need for a new model and proposed model is described in this paper.
With the development of new technologies and an increasing number of organizations that conducted digital transformation there is also a need for measuring the success of the made transformation. The model that is described in this paper give supply chain and organization within the supply chain opportunity to measure their maturity level and success of conducted digital transformation. With increasing in the maturity of digital transformation there is also risk related to substituting the need for human labor in supply chain and organizations at the whole that may lead to creating a self-sufficient system. One of the limitation of this paper is the cost of implementing new technologies in opposite to benefits from the digitalization of supply chain and raising the level of its maturity. There is also a need to quantify each indicator for every level of maturity.

Future researches in this area are advised to upgrade the model described in this paper with methodology that will enable to quantify success in conducting transformation. For example, to weigh all implemented technologies and based on the sum of weigh to give conclusion in which state of maturity level organization is.

\section{REFERENCES}

[1] Kozarević, S. \& Puška, A. (2015). Povezanost primjene lanca opskrbe, partnerskih odnosa i konkurentnosti. Ekonomska misao i praksa, 10(2), 579-596. (in Croatian)

[2] Ebert, C. \& Duarte, C. H. C. (2018). Digital Transformation. IEEE Software, 35(4), 16-21. https://doi.org/10.1109/MS.2018.2801537

[3] Chanias, S. \& Hess, T. (2016). Understanding Digital Transformation Strategy formation: Insights from Europe's Automotive Industry. Conference Proceedings of the $20^{\text {th }}$ Pacific Asia Conference on Information Systems (PACIS 2016), Chiayi, Taiwan, p. 296.

[4] Proença, D. and Borbinha, J. (2016). Maturity models for information systems - A state of the art. Procedia Computer Science, 100, 1042-1049. https://doi.org/ 10.1016/j.procs.2016.09.279

[5] Wilson, M. P. (2015). General System Theory: Towards the Unification of Science. Proceedings of the $58^{\text {th }}$ Annual Meeting of the ISSS-2014, 1(1), United States.

[6] Žaja, M. (1993). Poslovni sustavi. Zagreb: Školska knjiga. (in Croatian)

[7] Verina, N. \& Titko, J. (2019). Digital transformation: conceptual framework. Contemporary Issues in Business, Management and Economics Engineering 2019, 719-727. https://doi.org/10.3846/cibmee.2019.073

[8] Buntak, K., Kovačić, M., \& Martinčević, I. (2020). Technical and technological competence as foundation for digital transformation. 21 st International Symposium on Quality. Quality - Yesterday, Today, Tomorrow. Proceedings. https://doi.org/10.30657/hdmk.2020.08

[9] Buntak, K., Adelsberger, Z., \& Adelsberger, D. (2011). Utjecaj upravljanja intelektualnim kapitalom na organizacijsku kompetentnost. Sistem kvaliteta uslov za uspešno poslovanje $i$ konkurentnost. Proceedings. Kopaonik.

[10] Ivančić, L., Vukšić, V. B., \& Spremić, M. (2019). Mastering the digital transformation process: business practices and lessons learned. Technology Innovation Management Review, 9(2), 36-50. https://doi.org/10.22215/timreview/1217

[11] Osmundsen, K., Iden, J., \& Bygstad, B. (2018). Digital Transformation: Drivers, Success Factors and Implications. 
The $12^{\text {th }}$ Mediterranean Conference on Information Systems (MCIS), Korfu, Greece.

[12] Kantasa-ard, A., Bekrar, A., and Sallez, Y., 2019. Artificial intelligence for forecasting in supply chain management: a case study of White Sugar consumption rate in Thailand. IFACPapersOnLine, 52(13), 725-730. https://doi.org/10.1016/j.ifacol.2019.11.201

[13] Ngo, T. D., Kashani, A., Imbalzano, G., Nguyen, K. T., \& Hui, D. (2018). Additive manufacturing (3D printing): A review of materials, methods, applications and challenges. Composites Part B: Engineering, 143, 172-196. https://doi.org/10.1016/j.compositesb.2018.02.012

[14] Abdel-Basset, M., Manogaran, G., \& Mohamed, M. (2018). Internet of Things (IoT) and its impact on supply chain: A framework for building smart, secure and efficient systems. Future Generation Computer Systems, 86, 614-628. https://doi.org/10.1016/j.future.2018.04.051

[15] Agrawal, P. \& Narain, R. (2018). Digital supply chain management: An Overview. IOP Conference Series: Materials Science and Engineering, $2^{\text {nd }}$ International Conference on Advancements in Aeromechanical Materials for Manufacturing, Vol. 455, 13-14 July, Telangana, India. https://doi.org/10.1088/1757-899X/455/1/012074

[16] Tjahjono, B., Esplugues, C., Ares, E., \& Pelaez, G. (2017). What does industry 4.0 mean to supply chain? Procedia Manufacturing, 13, 1175-1182. https://doi.org/10.1016/j.promfg.2017.09.191

[17] Iddris, F. (2018). Digital supply chain: survey of the literature. International Journal of Business Research and Management, 9(1), 47-61.

[18] Büyüközkan, G. \& Göçer, F. (2018). Digital Supply Chain: Literature review and a proposed framework for future research. Computers in Industry, 97, 157-177. https://doi.org/10.1016/j.compind.2018.02.010

[19](2019). Measuring progress: The digital supply chain transformation maturity model. Available: https://www.eohinforservices.com/wp-content/uploads/ 2019/03/Measuring-progress-the-digital-supply-chaintransformation-maturity-model.pdf (26. 10. 2020).

[20] Teichert, R. (2019). Digital Transformation Maturity: A Systematic Review of Literature. Acta Universitatis Agriculturae et Silviculturae Mendelianae Brunensis, 67(6), 1673-1687. https://doi.org/10.11118/actaun201967061673

\section{Authors' contacts:}

Krešimir Buntak, izv. prof. dr. sc. Sveučilište Sjever,

Trg dr. Žarka Dolinara 1, 48000 Koprivnica, Croatia

kresimir.buntak@unin.hr

Matija Kovačić, mag. ing. traff.

(Coresponding author)

Sveučilište Sjever,

Trg dr. Žarka Dolinara 1, 48000 Koprivnica, Croatia

matkovacic@unin.hr

Maja Mutavdžija, mag. ing. traff.

Sveučilište Sjever,

Trg dr. Žarka Dolinara 1, 48000 Koprivnica, Croatia

mamutavdzija@unin.hr 